\title{
ESTIMATION OF SIMPLE AND COMPLEX RESPONSE TIME DEVELOPMENT USING REGRESSION ANALYSIS
}

\author{
JANUSZ JAWORSKI ${ }^{1}$, ELIGIUSZ MADEJSKI², GRAŻYNA KOSIBA², SYLWIA WIATR ${ }^{3}$ \\ ${ }^{1}$ The University School of Physical Education in Krakow, Faculty of Physical Education, Institute of Sports, \\ Department of Sports Theory and Anthropomotorics \\ ${ }^{2}$ The University School of Physical Education in Krakow, Faculty of Physical Education, Institute of Social \\ Sciences, Department of Theory and Methodology of Physical Education \\ ${ }^{3}$ Doctoral Studies at The University School of Physical Education in Krakow
}

\author{
Mailing address: Janusz Jaworski, The University School of Physical Education, \\ Department of Sports Theory and Anthropomotorics, 78 Jan Paweł II Ave., 31-571 Kraków, \\ tel.: +48 12 6831048, fax: +48 12 6831121, e-mail: wajawors@cyf-kr.edu.pl
}

\begin{abstract}
Introduction. The aim of the study was to determine the age, level of achieving maximum results and growth of reaction time dynamics. Materials and methods. The study included 567 males of age between 7 and 22 years. Study materials included the results of simple reaction time and complex reaction time during progressive period. Conclusions. Progressive period of results' development lasts until the age of about 17-17.5, then stabilization of the analyzed results was observe. The most dynamic growth of all types of reaction time was observed in the analyzed 7 and 8-year-old boys.
\end{abstract}

Key words: reaction time, coordination motor abilities, the rural population

\section{Introduction}

For many years the coordination motor abilities (CMA) have been the subject of numerous scientific studies. Because of their special role, the researches were carried out, which allowed the isolation of specific CMAs, their internal structure and a variety of measurement methods [1, 2, 3, 4]. Regardless of the structuration concept in all CMA classifications, rapid response capability stands out. It allows for rapid initiation and execution of targeted, short-term motor operation in reaction to a specific signal, which may involve the whole body or its parts. Its level is indicated by the time elapsed since the activation signal to the completion of a specific movement, which is referred to as the response time $[2,5,6]$. It affects the efficiency of the following processes: formation of receptor stimulation, excitation transfer to the central nervous system, course of stimulation by nerve centers, and formation of operating signal, the signal path from the nervous system to the muscle, muscle stimulation with the change of its tension and the initiation of motion [6, 7]. Response time varies based on many factors, among others: on the genetic control power, the age and sex of respondents, the number and type of stimuli, the properties of the nervous system, stress, training time, and the sportive level, health status, functional asymmetry, the strength of the stimulus, the level of stimulation and fatigue, the interval between successive stimuli $[6,8,9,10$, $11,12,13,14,15]$. In psychology, there are three main types of response times $[16,17,18]$ : simple response time - involves response to predetermined individual signals (e.g. sound); differential response time - occurs when the respondent only reacts to certain stimuli, where they should cause response, and others should not cause any response; response time of choice involves choosing an appropriate motor response out of several possible.

The work of Donders of 1868 (quoted in [15]), should be considered as pioneering research on the response time demonstrated that simple response time is shorter than the response time of choice, and the longest among all is the differential response time. It is generally accepted that the average simple response time is about $220 \mathrm{~ms}$, and the average differential response time is $384 \mathrm{~ms}$. The variation of times depending on the type of stimulus is also observed. In many scientific studies, it was found that the response to the sound stimulus is faster than response to visual stimulus. Average auditory response times oscillate within the limits of $140-160 \mathrm{~ms}$, and the response time to visual stimuli $-180-200 \mathrm{~ms}$ [12]. It is clear that the response time increases with the number of possible stimulus-response reactions. In the literature, this relationship is described as Hick's law [19], which states that the response time increases in direct proportion to the logarithm of the number of stimulus-response pairs. According to this law, with two pairs of stimulus-response reaction time is extended by about $58 \%$ as compared to the simple response time. When further increasing the number of possible choices, the reaction time increases, but not as intensely as before. With the increase of the number of stimulus-response choices from 9 to 10, the response time is increased only about 2-3\% [18].

As is clear from a cursory analysis of the literature there are no works determining the age at which individuals achieve maximum results, and information what is the growth dynamics of simple response time (to visual and auditory stimuli) and the complex response time during progressive period. This information was the primary objective of this research. The study and the results obtained will therefore constitute basis for answers the following research questions:

1. What is the age at which respondents represent the peak (best) performance of response times tested?

2. What is the level of peak performance of tested types of response times? 
3. Does the set course of regression equations coincide with arithmetic averages obtained from the research?

4. What is the dynamics of the tested response time increments depending on their type and age of the subjects?

\section{Material and methods}

Study materials included the results of simple response time to visual, auditory stimulus and complex response time (with choice). The research was conducted in the years 20062012. The study covered 567 males of ages between 7 and 22 years, from the rural area population of Kraków. Continuous research was conducted on subjects between 7 and 11 years. From the age of 14 years a cross-sectional material was available. The subjects were arbitrarily divided into 7 groups according to their chronological age (Tab. 1).

Before the first evaluated test, each subject underwent a test, which was not recorded. The test was stopped when the trainer noticed that the tested person completely understands what the test is about. The subject always performed the test with dominant hand. The study used a portable Toshiba Satellite R15 tablet with touch screen and specially developed Jaworski's computer test [20]. The study was conducted in a separate room that was peaceful and quiet.

The scope of research covered:

- simple response time to visual stimulus. The subjects responded as soon as possible (by pressing the left mouse button) to the white square emerging centrally. 10 tests were performed, 2 extreme best and worst results were discarded. Of the remaining results, the arithmetic average was calculated, the result was expressed in ms;

- simple response time to auditory stimulus. The subjects responded as quickly as possible (by pressing the left mouse button) to the laptop-generated sound signal. 10 tests were performed, 2 extreme best and worst results were discarded. Of the remaining results, the arithmetic average was calculated, the result was expressed in ms;

- complex response time (with choice). The subjects responded as quickly as possible (in accordance with the instructions by pressing the left or right mouse button) to the emerging central white square or audible signal generated by the laptop. 10 tests were performed, 2 extreme best and worst results were discarded. Of the remaining results, the arithmetic average was calculated, the result was expressed in ms.

In all three cases the so called absolute response time was recorded, which is the total measure of sensory and motor component (pre-motor response time - only possible to assess using of the EMG signal + motor time - the growth of muscle activity to make a move). Thus, in the tests the time from the appearance of the stimulus until pressing the mouse was recorded. This type of measurement is particularly important in sport as well as in medical research. The terms "simple and complex response time" should be understood like that in rest of the study.

Statistical methods of the materials' development:

1. The basic statistical characteristics of response times studied in the distinguished fractions and chronological age, and for each category of response times were calculated.

2. On the basis of curvilinear regression equations the chronological age of subjects achieving the best result for each type of response time were determined.

3. Using curvilinear regression equations the level of the best result for each category of response times was also determined.

4. The indicators of developmental progress and the pace of development of the analyzed response times (in \% of the first year of the study) were calculated. The value of the skills at age 7 was assumed as $100 \%$ [21].

\section{Results}

The level of analyzed response times of males in the distinguished age groups of the chronological age are shown in Table 1. It includes arithmetic averages defined on the basis of research results, as well as designated on the basis of curvilinear regression equations. According to the analysis of arithmetic averages in the development of each ability, we can distinguish two periods: the progressive period and the period of relative stability results (in the last age group).

Already a preliminary analysis of the results in Table 1 demonstrate that the best result in response times fell between the averages in age group of junior high school students and academic students. In order to accurately estimate the minimum average response time and the age at which it is derived, second degree curvilinear regression equations were used. These equations, together with the level of development of the analyzed response times are presented in Figure 1.

According to the analysis of Figure 1, the course of designated regression equations almost fully coincides with arithmetic averages obtained from studies for the given chronological age. This pattern was particularly evident in the age range 7 to 15 years. A very good fit to the actual data of the proposed regression equations is also confirmed by a very high $\mathrm{R}^{2}$ rate. The model proposed for males explained between 97-98\% of the variability of visual and auditory response time and up

Table 1. Arithmetic average values of the analyzed response times in distinguished male chronological age groups (ms)

\begin{tabular}{|c|c|c|c|c|c|c|}
\hline \multirow{4}{*}{ Chronological age group } & \multicolumn{6}{|c|}{ Males } \\
\hline & \multicolumn{2}{|c|}{ Visual response time } & \multicolumn{2}{|c|}{ Auditory response time } & \multicolumn{2}{|c|}{ Complex response time } \\
\hline & Result of research & $\begin{array}{l}\text { The result of the } \\
\text { regression equation }\end{array}$ & Result of research & $\begin{array}{l}\text { The result of the } \\
\text { regression equation }\end{array}$ & Result of research & $\begin{array}{l}\text { The result of the } \\
\text { regression equation }\end{array}$ \\
\hline & $\bar{x}$ & $\bar{x}$ & $\bar{x}$ & $\bar{x}$ & $\bar{x}$ & $\bar{x}$ \\
\hline $7(\bar{x}=7.35)$ & 406.67 & 379.23 & 342.86 & 325.33 & 711.15 & 662.83 \\
\hline $8(\bar{x}=8.35)$ & 349.32 & 357.51 & 304,07 & 307.32 & 611.12 & 615.44 \\
\hline $9(\bar{x}=9.35)$ & 321.94 & 335.78 & 275.09 & 289.32 & 540.63 & 568.06 \\
\hline $10(\bar{x}=10.35)$ & 300.03 & 314.06 & 265.36 & 271.32 & 491.31 & 520.67 \\
\hline $11(\bar{x}=11.35)$ & $286.04)$ & 292.34 & 250.37 & 253.31 & 453.42 & 473.28 \\
\hline $\begin{array}{c}\text { Junior High School } \\
\quad(\bar{x}=14.26)\end{array}$ & 244.20 & 229.24 & 209.93 & 201.02 & 368.60 & 335.64 \\
\hline $\begin{array}{l}\text { Academic students } \\
\qquad(\bar{x}=19.93)\end{array}$ & 235.65 & 216.71 & 202.71 & 199.35 & 382.71 & 338.47 \\
\hline
\end{tabular}


about $99 \%$ of the complex response time. Thus, based on the determined second degree regression equations one may determine the age of achieving the best possible result and its level with a high accuracy. The corresponding data for both parameters are shown in Table 2.
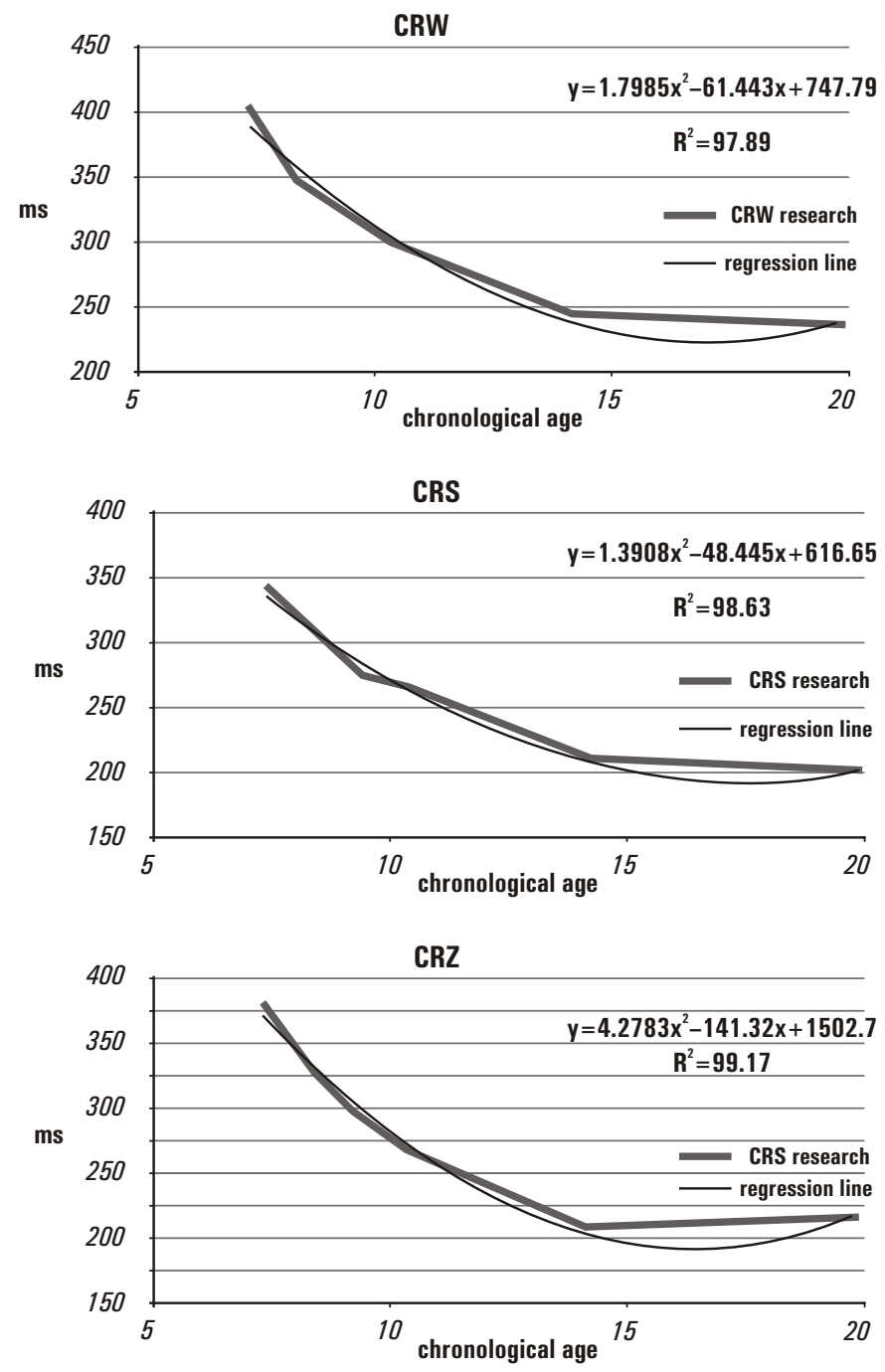

Key: CRW - visual response time, CRS - auditory response time, CRZ - complex response time

Figure 1. Changes in the level of tested response times during progressive period, according to the age

Based on the data presented in Table 2, it can be concluded that the period for obtaining the best results in visual response time is the age of about 17 years. Then, the auditory response time - the age of about 17.5 years. In turn, almost a year younger the boys presented the best results in complex response times. And analyzing the results according to the category of the test time, it was found that the best results were obtained for auditory response time $(194 \mathrm{~ms})$, then a visual response time (223 $\mathrm{ms}$ ) and finally complex response time (335 ms). Based on the drawn curvilinear regression line one may conventionally assume that the stabilization period (best results) of the times analyzed is at the age between 17 and 20 years of age.

With material from continuous research, and bearing in mind the above described regularities, the analysis also dealt with assessment of the development level and growth of dy- namics of different types of response times. The value of skills in the first year of research was assumed as $100 \%$. Suitable data of the analyzed response times are shown in Table 3. The most dynamic growth of all types of response times were observed between 7 and 8 years of age of the tested boys. This amounts to approximately $11 \%$ and $14 \%$ depending on the type of response analyzed. From the age of approximately 11 years, the growth dynamics rate considerably decreases, as is only about $3 \%$. The total increase in skills discussed (in relation to the result in 7 years of age) was approximately $41-47 \%$.

Table 2. Age of achievement of the best result and its level (in ms) determined on the basis of the curvilinear regression equations

\begin{tabular}{|c|c|c|c|c|}
\hline \multirow{2}{*}{ Variable } & \multicolumn{4}{|c|}{ Males } \\
\hline & $\begin{array}{l}\text { Age of achieving } \\
\text { the best result }\end{array}$ & $\begin{array}{c}\text { Best score } \\
\left(x_{\min }\right)\end{array}$ & \multicolumn{2}{|c|}{ Parameter } \\
\hline \multirow{2}{*}{$\begin{array}{c}\text { Visual } \\
\text { response time }\end{array}$} & \multirow[t]{2}{*}{17.08} & \multirow[t]{2}{*}{223.01} & $\begin{array}{c}\text { The regression } \\
\text { equation }\end{array}$ & $\begin{array}{l}y=1.7985 x^{2}- \\
61.443 x+747.79\end{array}$ \\
\hline & & & $\mathrm{R}^{2}[\%]$ & 97.89 \\
\hline \multirow{2}{*}{$\begin{array}{l}\text { Auditory } \\
\text { response time }\end{array}$} & \multirow[t]{2}{*}{17.42} & \multirow[t]{2}{*}{194.61} & $\begin{array}{c}\text { The regression } \\
\text { equation }\end{array}$ & $\begin{array}{l}y=1.3908 x^{2}- \\
48.445 x+616.65\end{array}$ \\
\hline & & & $\mathrm{R}^{2}[\%]$ & 98.63 \\
\hline \multirow{2}{*}{$\begin{array}{l}\text { Complex } \\
\text { response time }\end{array}$} & \multirow[t]{2}{*}{16.52} & \multirow[t]{2}{*}{335.69} & $\begin{array}{c}\text { The regression } \\
\text { equation }\end{array}$ & \begin{tabular}{|l}
$y=4.2783 x^{2}-$ \\
$141.32 x+1502.7$
\end{tabular} \\
\hline & & & $\mathrm{R}^{2}[\%]$ & 99.17 \\
\hline
\end{tabular}

Table 3. The advancement and dynamics growth of the tested ability in males

\begin{tabular}{|c|c|c|c|c|c|c|c|c|}
\hline & \multirow{7}{*}{ Result of research } \\
\cline { 3 - 9 } Variable & \multirow{2}{*}{ Parameter } & \multicolumn{7}{|c|}{ Age } \\
\cline { 3 - 9 } & & 7 & 8 & 9 & 10 & 11 & 14.26 & 19.93 \\
\hline & & 100 & 85.90 & 79.16 & 73.78 & 70.34 & 60.04 & 57.94 \\
\hline $\begin{array}{c}\text { Visual } \\
\text { response time }\end{array}$ & $\mathrm{ZR} \%$ & - & -14.10 & -6.74 & -5.38 & -3.44 & -10.30 & -2.10 \\
\hline $\begin{array}{c}\text { Auditory } \\
\text { response time }\end{array}$ & $\mathrm{ZR} \%$ & 100 & 88.68 & 80.23 & 77.39 & 73.02 & 61.22 & 59.12 \\
\cline { 2 - 9 } & $\mathrm{d} \%$ & - & -11.32 & -8.65 & -2.84 & -4.37 & -11.80 & -2.10 \\
\hline $\begin{array}{c}\text { Complex } \\
\text { response time }\end{array}$ & $\mathrm{ZR} \%$ & 100 & 85.93 & 76.02 & 69.08 & 63.75 & 51.83 & 53.81 \\
\cline { 2 - 9 } & $\mathrm{d} \%$ & - & -14.07 & -9.91 & -6.94 & -5.33 & -11.92 & 1.89 \\
\hline
\end{tabular}

ZR\% - progress of feature development in age category $n$, where \% value of the first test at the age of $7 ; \mathrm{d} \%=\mathrm{ZR} \%$ - ZR\% where: ZR\% value of the feature in age category $n(\%), Z R \%_{n-1}$ value of feature in the previous year of study (\%)

\section{Discussion}

To test the simple and complex response time a specially designed computer program was used that runs on a tablet. The inspiration for this approach involved developed and improved for many years computer tests of coordination motor abilities $[22,23]$. Authored set of tests has been successfully verified in pilot studies in terms of reliability and validity, i.e. very important criteria for the credibility of test use in practice. Indicators of the reliability of authored test set ranged from 0.76 to 0.93 [20]. Thus it was characterized by appropriate integrity for this type of tools - also postulated in other studies [22, 23, 24, 25].

As mentioned in the introduction, one of the factors influencing the level of response time are genetic conditions. By far the most numerous studies related to genetic simple response time, determined on the basis of twin studies. In contrast, most studies of simple response time heritability based on family materials were so far carried out in Poland (review of studies [26]). In general, based on the data we can conclude that high levels of 
heritability of this feature were demonstrated in earlier work based on the materials of twins $\left(\mathrm{h}^{2} 0.56\right.$ to 0.86$)$, whereas the results of recent, methodologically correct work do not support these suggestions. In turn, family studies suggest that the heritability of the characteristic indicators is in the range from 0.18 to 0.56 . Thus, simple response time belongs to features of a weak genetic control. There is a very modest output relating to the power of genetic conditioning of complex response time $[20,27]$. On the basis of only two reports one certainly cannot draw a clear conclusion about the strength of genetic control.

Then a very important factor in determining the level of response time is the kind of stimulus to which respondents respond. In own studies, a very characteristic pattern of the arithmetic averages of the times was obtained. Namely, the best results were obtained for auditory response time, then visual response time, and finally response time of choice. This pattern is evident in each chronological age group. The results obtained are also confirmed by the data of other authors [12, 15, 28]. To some extent, it is probably due to the way the stimulus reaching the brain. Research shows that the auditory stimulus reaches the brain in about 8-10 ms [29], and visual stimulus only after about 20-40 ms [30]. The difference between the distinguished types of responses is maintained regardless of whether we are dealing with the simple or complex response [31]. In turn, the response time to touch is located between the results of the visual and auditory response time and equals to the average of about $155 \mathrm{~ms}$ [17]. Also, the results [32] confirm that shortest response times are to the auditory and sensory stimuli, which is caused by the fast processing of audio information by auditory receptors and short duration of the afferent impulse transmission to the brain.

Another very important factor influencing the response time is the age of the respondents. The results of comparative studies indicate that until the age of about 20 years we are dealing with a period of progress. The obtained own results also confirm the observations. During the entire period studied there occurred improvement in performance, and peak capabilities were observed between 17 and 20 years of age. In turn, based on years of longitudinal research, Hirtz [33] found that at age of 17 the response time reaches its maximum. Similar timeframes were also obtained in the present study. Then, until about 50-60 years of age gradual deterioration of results is observed. The rapid involution changes in both sexes are noted after approximately 70 years of age $[12,34,35]$. However, given the intra-individual diversity it should be noted that already in the progressive period, in the area of coordination capacity in approximately $20 \%$ of subjects stagnation is noted, and even regress in $10 \%$ [36, 37]. Many cited authors emphasize that coordination capacity develop in different directions, but the greatest increases are observed between 7 and 11-12 years of age. The results of their ongoing research regarding the growth dynamics of response time, are also consistent with these observations.

\section{Conclusions}

On the basis of the presented research results, the following conclusions consistent with the purpose of the work may be drawn:

1. Tested response times indicated that the progressive period of results development lasts until the age of about 17-17.5 years, then the analyzed ability stabilizes.

2. A system of response times depending on the category was characteristic. The shortest time was obtained for the auditory response, then visual, and then the longest for the complex response.

3. Peak scores were presented by the subjects at earliest time in the case of complex response time, a little later in the case of visual response, and at the end in the case of auditory response.

4. The most dynamic growth of all types of response times was observed between the age of 7 and 8 in tested boys.

\section{Literature}

1. Szopa J., Mleczko E., Żak S. (1996). The basic of anthropomotorics. Warszawa-Kraków: Wydawnictwo Naukowe PWN. [in Polish]

2. Raczek J., Mynarski W., Ljach W. (2003). Shaping and diagnosis of coordination motor abilities. Handbook for teachers, trainers and students. Katowice: AWF Katowice. [in Polish]

3. Starosta W. (2003). Motor coordination abilities. Significance, structure, shaping. Warszawa: Instytut Sportu. [in Polish]

4. Hirtz P., Forschungszirkel "N.A. Bernstain” (2007). Phenomena of the human motor development. Schorndorf: Hofmann. [in German]

5. Taware G.B., Bhutkar M.V., Bhutkar P.M., Doijad V.P., Surdi A.D. (2012). Effect of age on audio-visual and whole body reaction time. Al Ameen Journal of Medical Science 5(1), 9094.

6. Bańkosz Z., Nawara H., Ociepa M. (2013). Assessment of simple reaction time in badminton players. Trends in Sport Sciences 1(20), 54-61.

7. Maćkała K., Cych P. (2011). Factors influencing the response time in teaching and perfecting low start. Rozprawy Naukowe AWF we Wrocławiu 33, 5-11. [in Polish]

8. Lord S.R., Fitzpatrick R.C. (2001). Choice stepping reaction time a composite measure of falls risk in older people. The Journals of Gerontology Series A 56(10), 627-632. DOI: 10.1093/gerona/56.10.M627.

9. Luchies C.W., Shiffman J., Richards L.G., Thompson M.R., Baziun D., DeYoung A.J. (2002). Effect of age, step direction and reaction condition on the ability to step quickly. The Journals of Gerontology Series A 57(4), 246-249. DOI: 10.1093/gerona/57.4.M246.

10. Der G., Deary I.J. (2006). Age and sex differences in reaction time in adulthood: results from the United Kingdom health and lifestyle survey. Psychology and Aging 21(1), 62-73. DOI: 10.1037/0882-7974.21.1.62.

11. Kaarin J.A., Dear K., Christensen H., Jorm A.F. (2005). Biomarkers, health, lifestyle, and demographic variables as correlates of reaction time performance in early, middle, and late adulthood. The Quarterly Journal of Experimental Psychology 58A(1), 5-21.

DOI: $10.1080 / 02724980443000232$.

12. Kosinski R.J. (2008). A literature review on reaction time. Clemson University. Retrieved from http://biae.clemson.edu/bpc/bp/Lab/110/reaction.htm.

13. Saxena C., Kaur R., Arun P. (2008). Reaction time of a group of physics students. Physics Education 43(3), 309-313. DOI: org/10.1088/0031-9120/43/3/010.

14. Solanki J., Joshi N., Shah C., Mehta H.B., Gokhle P.A. (2012). A study of correlation between auditory and visual reaction time in healthy adults. International Journal of Medicine and Public Health 2(2), 36-38.

15. Apoorvagiri, Nagananda M.S. (2013). Mental stress and its implications on reaction time. International Journal of Computer Trends and Technology 4 (5), 1426-1430.

16. Welford A.T. (1980). Choice reaction time: basic concepts. In A.T. Welford (Ed.), Reaction times (pp. 73-128). New York: Academic Press.

17. Luce R.D. (1986). Response times: their role in inferring elementary mental organization. New York: Oxford University Press. 
18. Schmidt R.A., Wrisberg C.A. (2010). Development of motor skills. Warszawa: Centralny Ośrodek Sportu. [in Polish]

19. Hick W.E. (1952). On the rate of gain of information. Quarterly Journal of Experimental Psychology 4, 11-26.

20. Jaworski J. (2012). Environmental and family determinants of selected coordination motor abilities. Longitudinal study on children from rural areas aged 7 to 11 years. Monografie, Kraków: AWF Kraków. [in Polish]

21. Mleczko E. (1991). The course of and conditions affecting morfo-functional development in children from Krakow ages 7-14. Kraków: Wydawnictwo Monograficzne AWF Kraków. [in Polish]

22. Juras G., Waśkiewicz Z. (1998). Temporal, spatial, and dynamic aspects of coordination motor abilities. Studies of human motor skills 3, Katowice: AWF Katowice. [in Polish]

23 Klocek T., Spieszny M., Szczepanik M. (2002). Computer tests of coordination motor abilities. Warszawa: Centralny Ośrodek Sportu. [in Polish]

24. Domholdt E. (2000). Physical therapy research. Principles and applications ( $2^{\text {nd }}$ edition). Philadelphia: WB Saunders Co.

25. http://www.schuhfried.com/viennatestsystem10/tests-testsets/all-tests-from-a-z/. Retrieved 09.11.2013.

26. Lyakh V., Jaworski J., Wieczorek T. (2007). Genetic endowment of coordination motor abilities a review of family and twin research. Journal of Human Kinetics 17, 25-40.

27. Ljach W. (2002). The effect of genetic and environmental factors on the development of motor coordination abilities in children aged 7-10 years. Physical Education and Sport 2, 265-267.

28. Johne M., Poliszczuk T., Poliszczuk D., Dąbrowska-Perzyna A. (2013). Asymmetry of complex reaction time in female épée fencers of different sports classes. Polish Journal of Sport and Tourism 20(1), 25-34.
29. Kemp B.J. (1973). Reaction time of young and elderly subjects in relation to perceptual deprivation and signal-on versus signal-off condition. Developmental Psychology 8, 268-272.

30. Marshall W.H., Talbot S.A., Ades H.W. (1943). Cortical response of the anaesthetized cat to gross photic and electrical afferent stimulation. Journal of Neurophysiology 6, 1-15.

31. Sanders A.F. (1998). Elements of human performance: reaction processes and attention in human skill. Mahwah, New Jersey: Lawrence Erlbaum Associates Publishers.

32. Kandel E.R., Schwarz J.H., Jessell T.M. (2000). Principals of neural science. New York: McGraw-Hill.

33. Hirtz P. (1978). Accents of formation of the coordination capacity during physical education classes in grades 1 to 10 . Körperziehung 1, 340-344. [in German]

34. Rose S.A., Feldman J.F., Jankowski J.J., Caro D.M. (2002). A longitudinal study of visual expectation and reaction time in the first year of life. Child Development 73(1), 47-61.

35. Jaworski J., Tchórzewski D., Bujas P. (2011). Involution of simple and complex reaction times among people aged between 21 and 80 - the results of computer tests. Human Movement 12(2), 153-158. DOI: 10.2478/v10038-011-0013y.

36. Hirtz P. (1998). The individual variability of inter-individual motor development. (Ed. R. Ricken). St. Augustin: Academia. [in German]

37. Hirtz P., Dierks B., Holtz A., Ludwig G., Lühnenschloß D., Vilkner H.J., et al. (2012). Motor skills. Reaction. Schorndorf: Hofmann. [in German]

Submitted: November 25, 2013

Accepted: December 18, 2013 